To be presented at the Second Cairo Solid State Conference, organized by the American University in Cairo in cooperation with Ein Shams University, and sponsored by the U. S. National Science Foundation, April 21-26, 1973.

\title{
THE EFFECT OF POLAR GROUPS ON THE POST-IRRADIATION CONDUCTIVITY OF POLYSTYRENE**
}

\author{
W. W. Porkinson \\ Health Physics Division \\ Oak Ridge National Laboratory \\ Oak Ridge, Tennessee \\ M. J. Kelly \\ Reactor Chemistry Division \\ Oak Ridge National Laboratory \\ Oak Ridge, Tennessee \\ and \\ I. O. Salyer \\ Monsanto Research Corp. \\ Dayton, Ohio
}

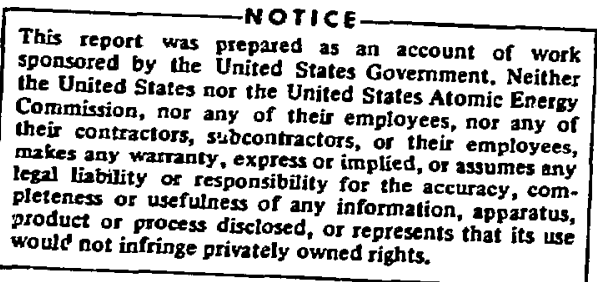

\section{INTRODUCTION}

For service in electrostatic, ion chamber type dosimeters, the requirements

for insulating materials are quite severe. Compact personnel dosimeters utilize a charge storage capacitor and the insulating material in this critical component must have very high resistivity. Although the conductance of this capacitor during exposure to ionizing radiation can be taken into accoun in the experimental calibration of the dosimeter, the conductance before and after irradiation will give spurious indications of radiation. Therefore, the conductance must be below minimum levels established by the tolerable errors for the dosimeter. Non-polar, hydrocarbon plastics have low conductivity and dielectric charging and good fabrication characteristics,

*Sponsored by the U. S. Army Electronics Command and the Defense Civil Preparedness Agency, under Union Carbide Corporation's contract with the U. S. Atomic Energy Commission. 
making them especially suitable for capacitor insulation. On the other hand, Fowler ${ }^{(1)}$ and others have reported for a number of years that the conductivity of a specific polymer during irradiation and the decay afterward varied considerably among samples, probably depending on impurities. The purpose of this study, then, was to determine the nature of the chemical species controlling the post-irradiation conductivity of hydrocarbon polymers and to explore the effects of incorporating known chemical groups in suitable polymers as a guide to formulation of improved materials for this demanding application. Most of the effort was concentrated on styrene-based polymers because of their good electrical and fabrication properties and the ease of synthesis and formulation.

\section{EXPERIMENTAL METHODS AND APPARATUS}

A. Apparatus for Electrical Conductivity and Dielectric Charging.

The electrical circuit for measurement of apparent conductivity, in essence, consisted of a source of known voltage and an amplifier with a known input resistance for measurement of very low currents. The potential source was comprised of mercury batteries, chosen for their stability, a divider network providing 5, 25, 50, 75, and 100 volfs, a potential reversing switch, and an RC noise filfer. The electrometer amplifier was a vibrating reed type, Cary Model 401, with input resistances of $10^{8}$, $10^{20}$ and $10^{23}$ ohms.

A block diagram of the measuring circuit is shown in Fig. 1. Its operation can be summarized briefly as follows. A selected potential (ordinarily $100 \mathrm{v}$ ) is applied from reference ground to the potential side of the film sample. This causes current to flow through the film dependirg on the potential applied, the dielectric 
G charge COLleigtion capacitor Cy VIBRATING REED CAPACITOR $A_{1} 10^{\circ}, 10^{10}$, GR 112 13 onms

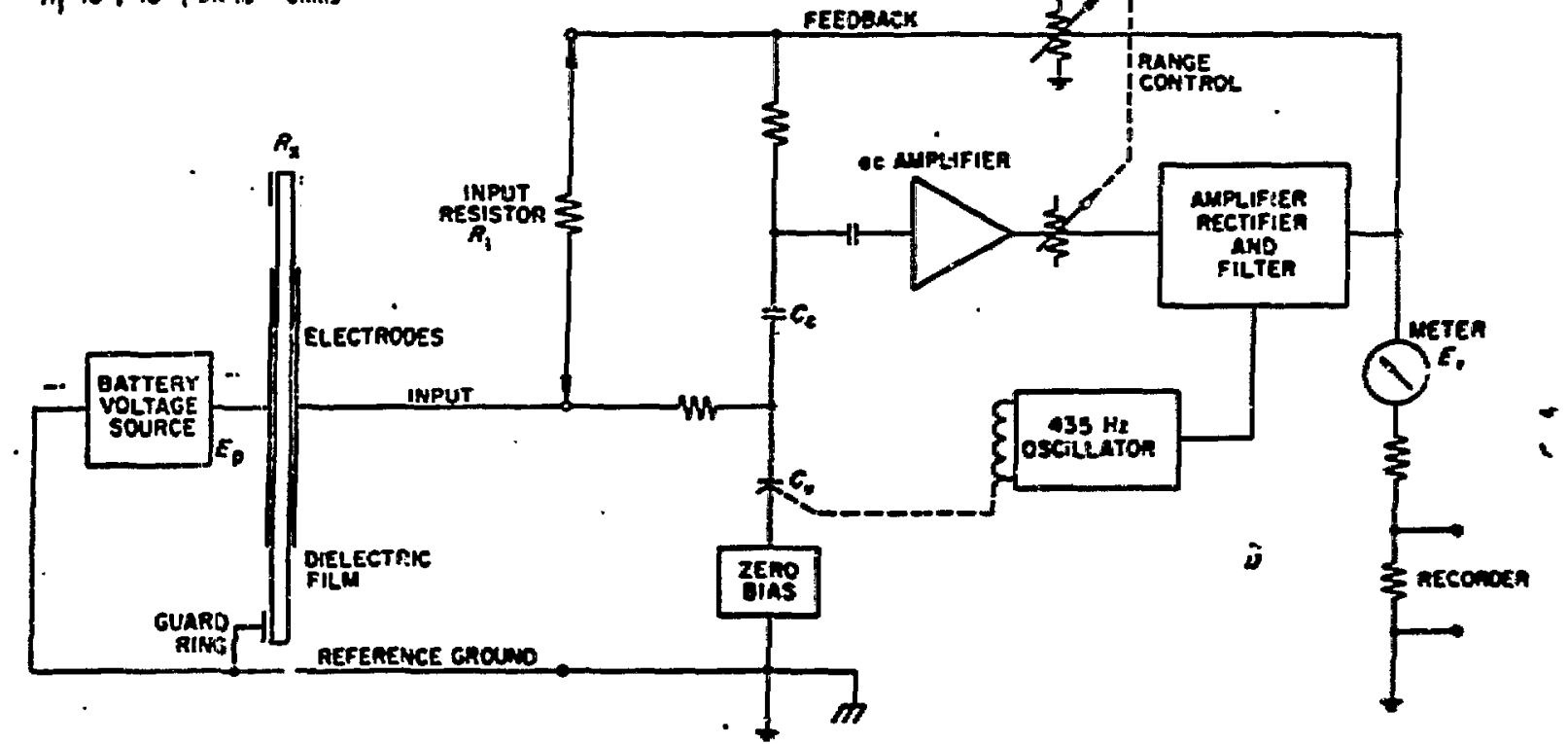

- Fig. 1 Block Diagram of Electrical Properties Mesurement C1rcuitry. 
charging properties of the film and on its ultimate ohmic resistance. The usual problem in high resistance circuits of leakage currents in parall el with the measuring amplifier has been avoided by using feedback from the elecirometer amplifier. The gain of the feedback amplifier is 1000 and the circuit parameters moke the output voltage, $E_{r}$ (30 volts maximum) equal to the potential across the input resistor, $R_{i}$. Then the maximum potential across the distributed resistance in parallel with the input (shunt resistance) is only $1 / 1000$ of the potential caused by current flowing through $\mathrm{R}_{i}$, in effect maltiplying the shunt resistance by 1000 for the equivalent resistance shunting $R_{\mathrm{i}}$. The actual value of this shunt resistance appearing in parallel with $R_{i}$ con be as low as $10^{2}$ ohms withouf giving errors in output of more than $10 \%$ when the input resistor of $10^{23}$ is in use. Since the output voltage, $E_{\mathrm{r}}$, is equal to the potential ocross $R_{i}$, approximatiens can be used in the equivalent circuit to give

$$
\frac{R_{x}}{E_{p}}=\frac{R_{i}}{E_{p}} .
$$

Letting $P=$ resistivity of the specimen, $d=$ thi ckness and $A=$ oreo, then:

$$
\rho=\frac{R_{i} E_{p} A}{E_{p} d}=\frac{1}{\sigma} .
$$

For measurement, the specimen was enclosed in a metal sample chamber which could be evacuated to eliminate moisture but usually the chamber atmosphere could be dried satisfactorily and more conveniently by anhydrous $\mathrm{C}_{a} \mathrm{SO}_{4}$ in the chamber. The copacitance of the specimens was measured by a conventional impedance bridge (General Radio Model 1650A). 
B. Specimen Preparation.

With the exception of a few plastics ovailable commercially as thin film, the polymers were synthesized by conventional emulsion polymerization or by freeradical initiated, mass polymerization. The emulsion produsts required exhaustive dryir before conversion to specimen films, in vacuum of $80^{\circ}-90^{\circ} \mathrm{C}$ for 24 to 48 hours.

Bulk polymer was converted to specimen film of about 0.001 inch thickness either by casting from solution or by blow extrusion where available quantities permitted. Typical specimen films (Fig. 2) had electrodes of 3 to 6 sq. inches to provide sufficient current for mec surement. The electretes were aluminum or gold, vapor deposited in yocuum with suitable masks over the specimen film to give the desired electrode shape.

C. Irradiation and Measursment.

After measurement for a sufficient time to establish the electrical properties without irradiation, the specimen was irradiated in dry air in the center of a $60^{\circ}$ Cobalt gamma source ${ }^{(E)}$ to a dose of 2000 rads at either 20 or 200 rads/sec. The specimen was then connected to the measurement circuit and conductivity was recorded over a decay period, usually $10^{5}$ seconds, to define the post-irradiation conductivity.

D. Treatment of Dafa.

For thin specimens the average thickness could not be measured as accurately as the capacitance, which depends on the dimensions of the electrode region in the 


$$
\overline{7}
$$


same manner as the conductance. The measured capacitance of the specimens, $C$, was used with the apparent resistance, $R_{\mathbf{x}}$, derived from the amplifier sutput, $E_{r^{\prime}}$ to calculcite the conductance-capacitance ratio, $\Sigma / C$, and

$$
\frac{\Sigma}{C}=\frac{1}{R_{x} C}=\frac{\sigma}{e e_{0}} \text {. }
$$

Then the apparent conductivity of the specimen, $\sigma$, can be calculated by multiplying $\Sigma / C$ by the product of the dielectric constant, $e_{z}$ and the permittivity of space, $e_{0}$. For styrene-based polymers $e=2.3$ to 2.5 and $e_{0}=$ about $2.1 \times 10^{-13} \mathrm{f} / \mathrm{cm}$.

In the measurement of specimens both before and after irradiation, the apparent conductance decreases with time owing to dielectric polarization. It has been shown ${ }^{(3)}$ that with the various dipoles in the polymer acting within the electric fields of their neighbors as well as within the external field, the time dependent dielectric constant is proportional to $t^{m}$. Then a $\log -\log$ plot of $\Sigma / C$ will have a slope of $-m$, approximately -1 for hydrocarbon polymers. Such a plot proves to be the most convenient form for presentation of the time-dependent electrical properties of these materials and the slope of -1 was noted for many specimens. This dielectric charging or decreasing apparent conductance can be related to dosimeter errors and the tolerable limits, $2 \%$ drift in 96 hours before irradiation and $5 \%$ drift for 4 hours following irradiation, are plotted for most specimens as convenient comparison levels.

\section{APPARENT CONDUCTIVITIES OF TYPICAL POLYMERS}

The apparent conductivities of some typical, high-resistivity polymers are shown in Fig. 3, plotted as described above. Predictably, the materials with polar 


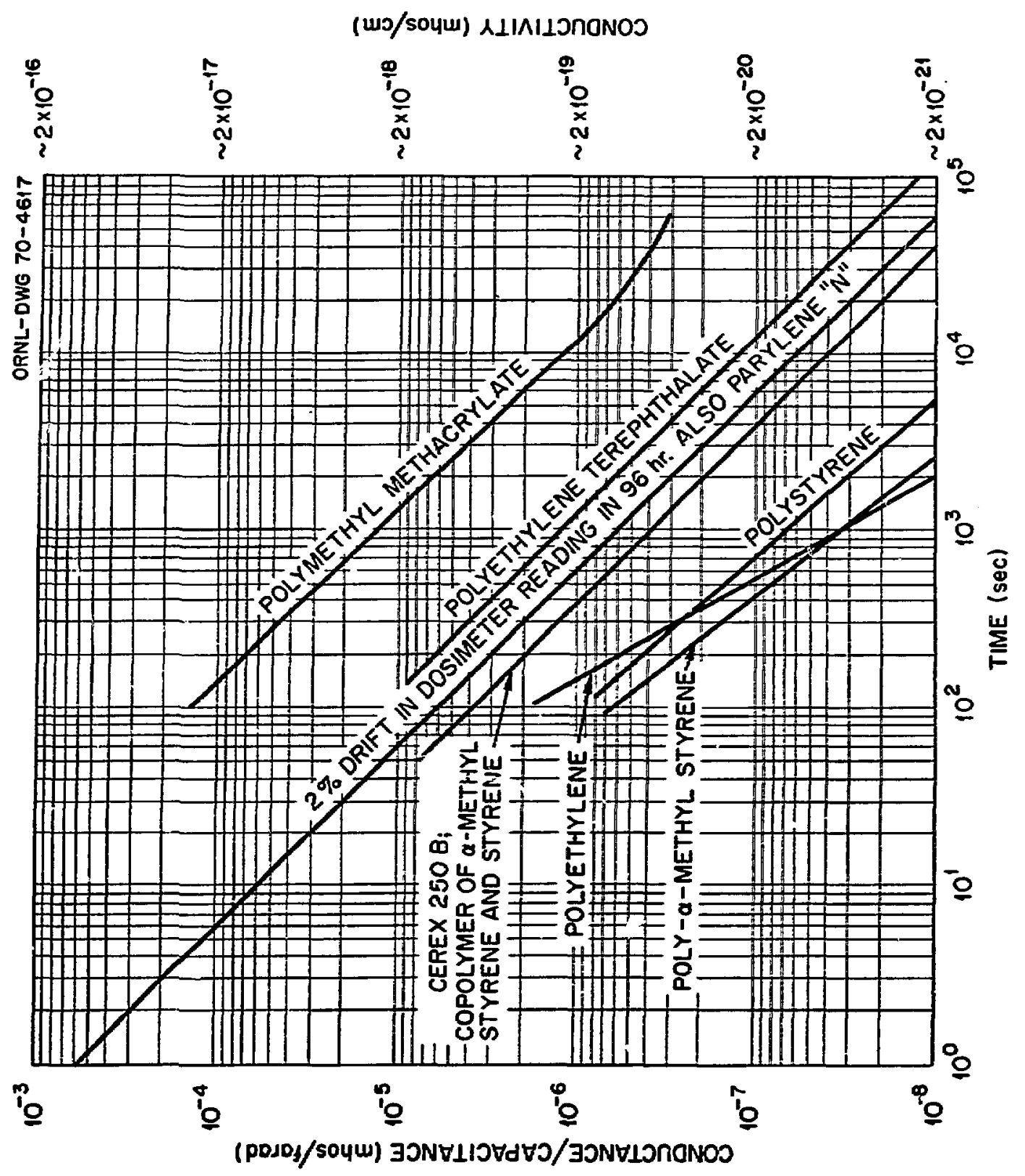


groups, polymethyl methacrylate with methyl carboxylate side groups and polyerhylene terephthalate with in-chain ester groups, give high dielectric polarization. Of greater inferest are the non-polar, hydrocarbon polymers with an order of magnitude lower dielectric charging. It is significant that the copolymer of styrene and $\alpha$-methyi styrene has relatively high dielectric charging, undoubtedly from polar groups incorporated by the emulsion polymerization preparation methad.

The conductance-capacitance ratios for most of these polymers after irradiation are shown in Fig. 4, and the values at suitable time intervals after irradiation or electrification for these and several other commercial plastics are listed in Table 1. It is significant that the apparent conductivities of all the materials except the styrene, methyl styrene copolymer, were more than an order of magnitude greater after irradiaiion than the values at corresponding times before irradiation.

\section{THE NATURE OF POST -IRRADIATION CONDUCTIVITY}

\section{A. General Considerations.}

The question immediately arises as to whether the decreasing apparent conductivity following irradiation is actual charge transport by mobile charge carriers or merely resientation of radiation-generated dipoles similar to the dielectric polarization prior to exposure to ionizing radiation. Furthermose, if post-irradiation conductivity is true charge transport, is the nature of the mobile carriers ionic or electronic? Both of these questions can be answered by the behavior of the apparent conductivity upon removing (short circuiting), reversing and delaying application of the applied potential, and by repeated measurements. 


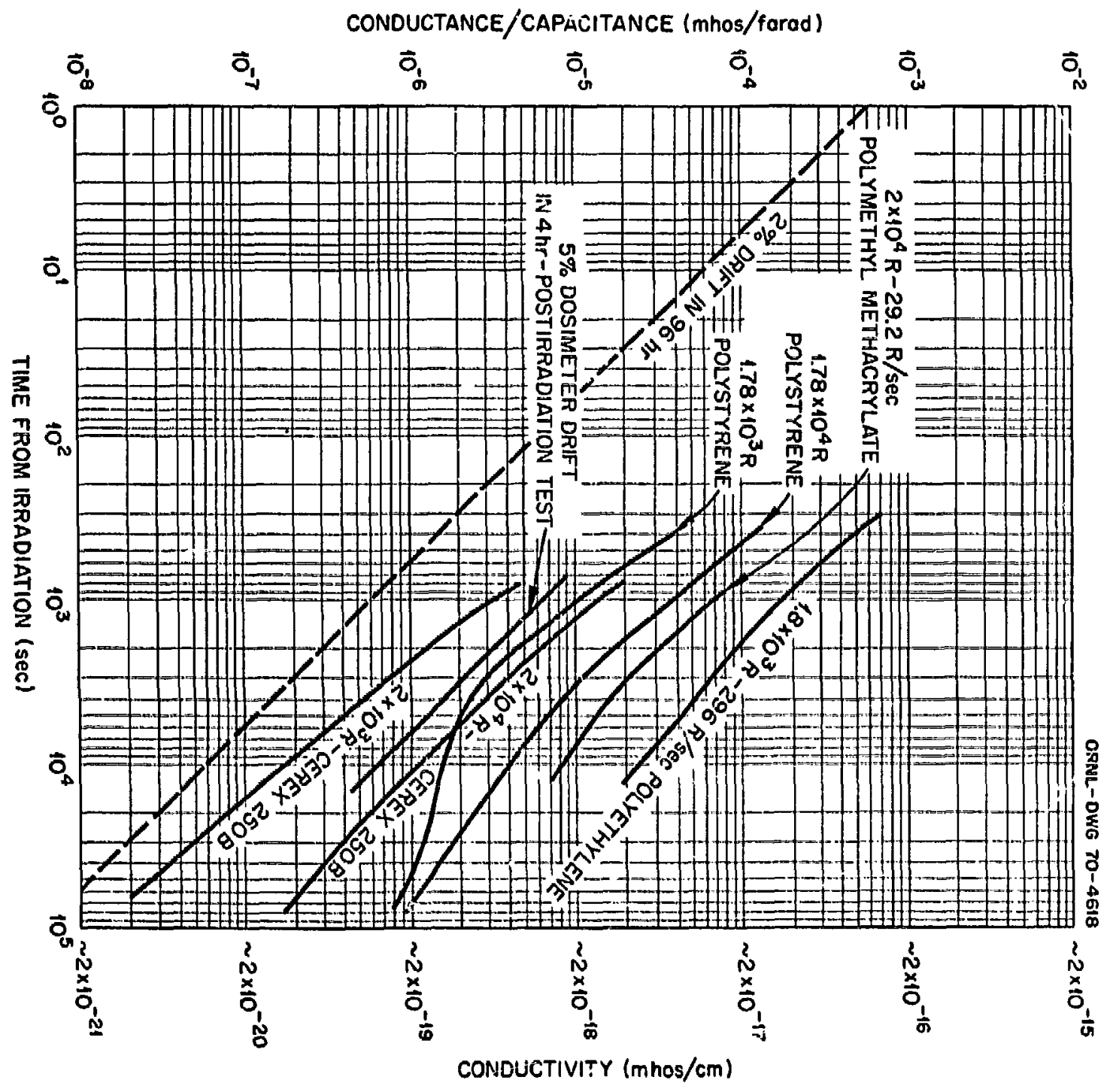


Table 1. Measured Conductance/Capacitance Ratios of Typical Plastics Before and After Irradiation

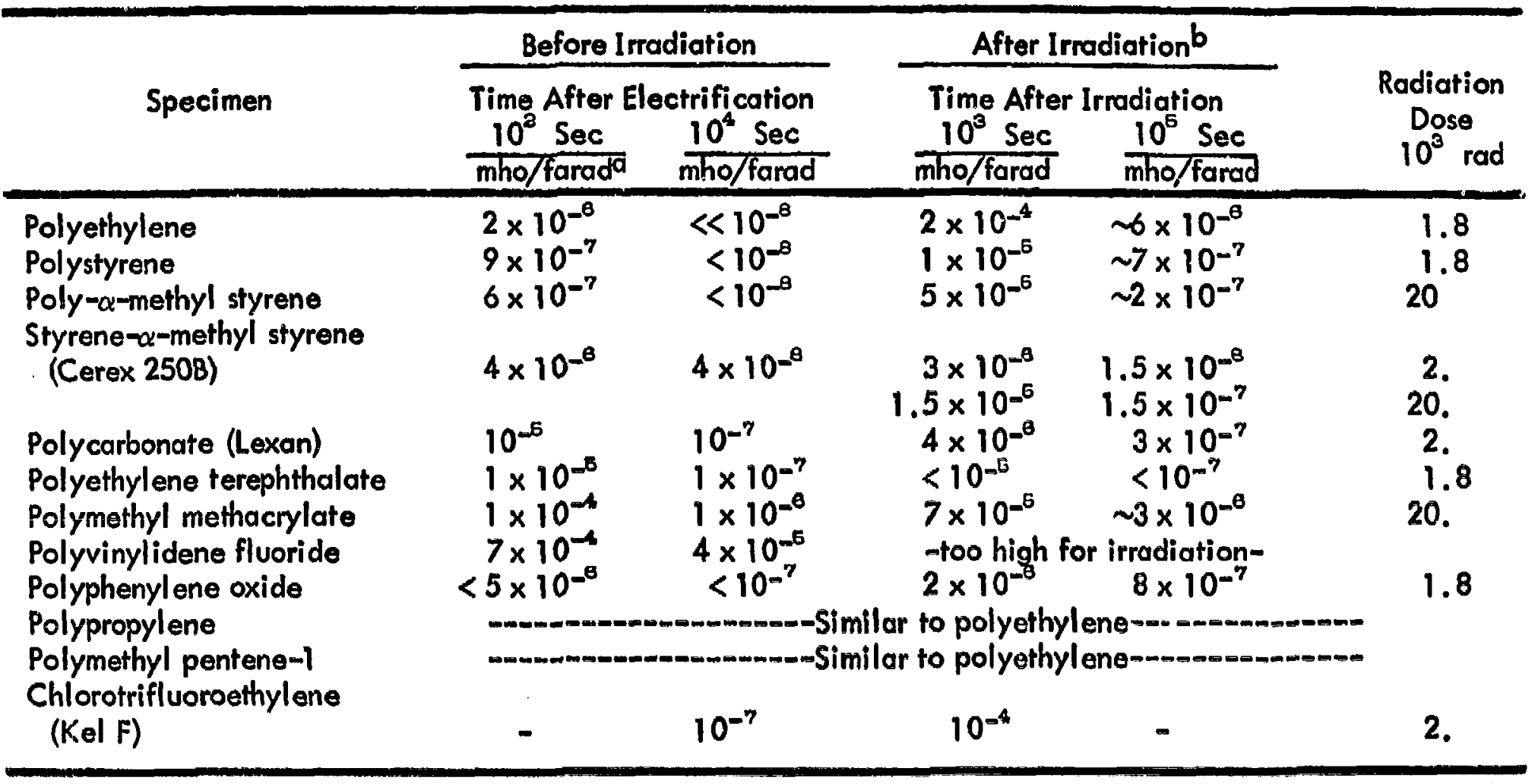

${ }^{a}$ To convert to $(\mathrm{ohm}-\mathrm{cm})^{-1}$ multiply by $\sim 2 \times 10^{-13}$.

${ }^{b}$ Electrification began $\sim 300 \mathrm{sec}$ after irradiation ceased. 
B. Removing, Reversing and Delaying Measuring Potential.

If the applied potential is removed (short circuited) from an unirradiated specimen after a long period of measurement such that the apparent conduction is approaching the steady state conductivity, the charge on the specimen electrodes will discharge through the electrometer as the specimen dielectric depolarizes under the influence of the internal electrical field. This depolarization current can be calculated as a conductance/ copacitance ratio using the known value of the specimen capacitance, the input resistance of the electrometer, and an assumed value of the internal field equal to the original applied potential. Under these conditions, the depolarization conduction (discharge current) as a function of time duplicates the original dielectric charging curve as can be seen in Fig. 5 and in many subsequent figures.

If the applied potential is reversed after lengthy measurement of an unirradiated sample $\left(10^{4} \mathrm{sec}\right)$ the depolarization current again will be similar to the original dielectric charging but double in value (and opposite in direction) under both the internal field and the reversed external potentiai. This can be seen in Fig. 5 where the distortion of the logarithmic scale has been eliminated by replotting with the time after reversal, $t_{r f}$ on the abscissa instead of the total time, $t_{t}\left(t_{r}=t_{t}-10,000\right)$. This behavior conforms with the theory of dielectric relaxation ${ }^{(3)}$ and is that to be expected of dielectric polarization. (4)

If a similar sequence of measurements is performed on a specimen after irradiation, upon short circuiting the applied potential, the depolarization or discharge current is very similar to both the dielectric charging and discharge curves before irradiation (Fig. 6). This suggests that the excess conductivity generated by radiation is NOT due 


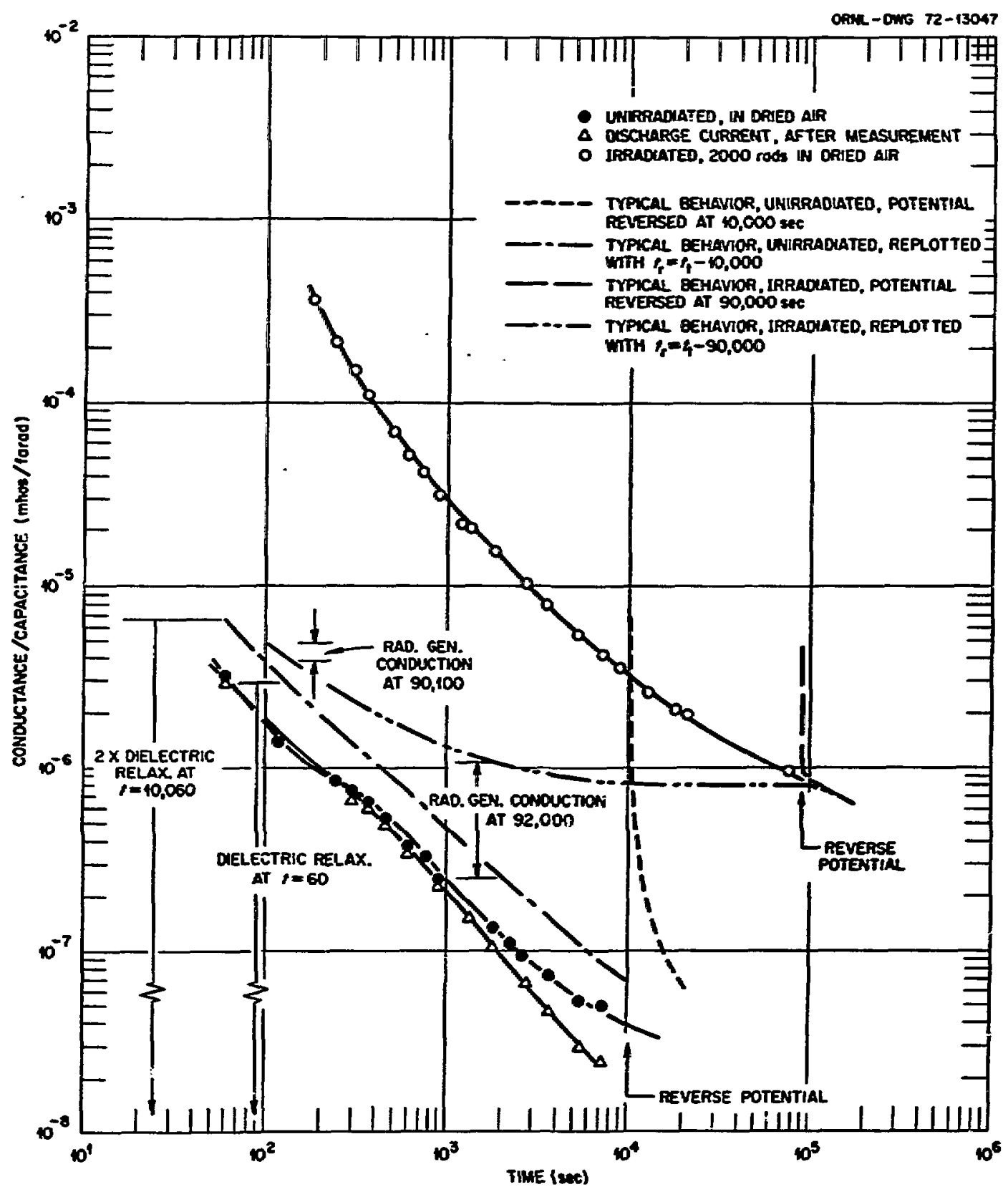

Typicol High-Purity Polystyrene (Film MR-0-3). 


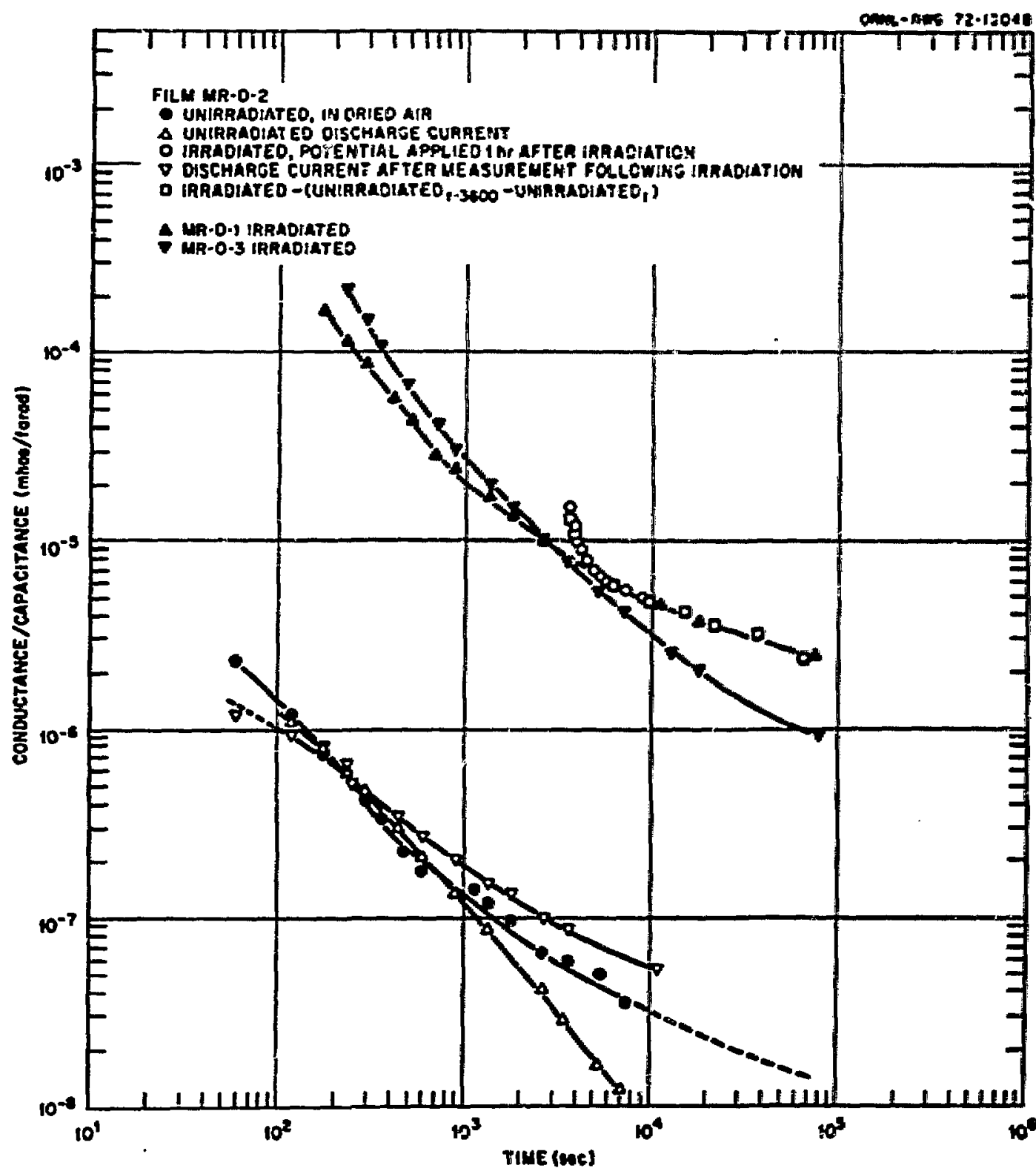

Polystyrene, No Initiotor, Mass Polymerized. 
to additional radiation-produced dipoles. Indeed, upon reversing the applied potential ofter lengthy measurement $(90,000$ sec) of on irrodiated specimen, the apporent conductivity is the sum of iwice the initial, unimadiated dielectric charging plus the low value of the radiation-induced conductivity remaining after the decoy period of measurement $(90,000$ sec). This typicol behavio is demonstrated in fig. 6 for high-purity polystyrene specimens. The curves for persulfoterinitiated, emulsion polymerized polymars (MRC-2500 type) were similar axeept that the higher dielectric charging and lower radiationgeneroted conduction made it difficult to discem the decayed rodiationinduced consuctivity suparimposed upon the initial dielectric charging.

If the post-irradiotion cor.Juctivity were dielectric chorging of rodiation-generoted polar pecies, the opporent conduction upon reversal of opplied potential of 90,000 sec would be opproximately twice the initial value of post-irradiotion conduction, unless a dererese or decoy of dipoles is assumed. But the decoy of conductivity in the irrodiated specimens generally wos no more ropid than in unirrodiated specimens, in which the rate of decoy (slope) is estoblithed by a broad spectrum of reloxotion times of dipolor species. For an imodiated spaciman containing o decreosing concentrotion of rodiation-generated dipoles to have a slope similor to an unirrodiated specimen would require thet the spectrum of relaxation times of rodiation generated dipoies motch in a unique the rote of decreose in concentration of dipoles. This is highly improbable. These considerotions indieste that the post-irrodiation conductivity is true charge tronsport rather than oriantation of radiation-produced dipoles.

Further conff rmation of this conclusion is observed by deloying opplicotion of measuring potential until 3600 sec ofter irradiation (figs. 6 and 7 . In these coses, recombination of the mobile charge carriers accurs following irradiation and, when 


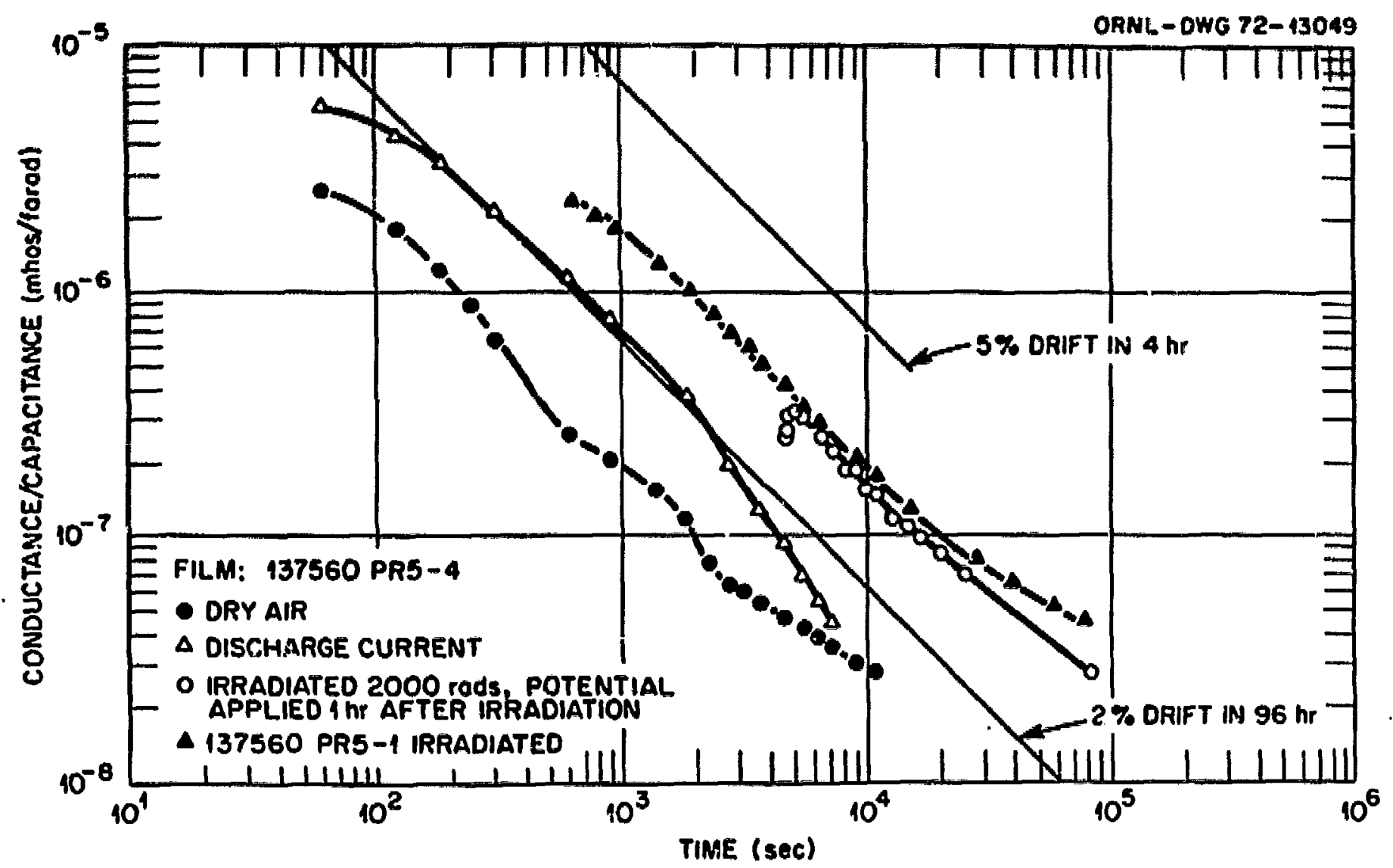

Polystyrene; Initiator: $\mathrm{K}_{2} \mathrm{~S}_{2} \mathrm{O}_{8}$, Emulsifier: Acto 450 , Production Run. 
potential is applied, the observed conduction is the sum of the decayed radiationgenerated conductivity after the 3600 -sec delay superimposed on the initial, unirradiated dielectric charging current. In Fig. 6 , the post-irradiation curve has been replotted (squares) with the difference between the initial unirradiated charging and that after the delay subtracted from the measured post-irradiation curve in an effort to generate a normal post-irradiation curve. The appearance of this difference curve (squares) indicates that the post-irradiation decoy of charge carriers was not as rapid in the absence of an externolly applied potential field, but in both Figs. 6 and 7 the coincidence between the delayed post-irradiation curves and normal eurves of similar specimens confirms the attribution of post-irradiation conductivity to mobile charge carriers of limited life-time.

The conduction mechanism is the same in the persulfate-initiated, emulsionpolymerized polystyrenes, as shown in Fig. 7, even though the post-irradiation conductivity is an order of magnitude lower than in high-purity polymers.

\section{Repeated Measurement and Irradiation.}

As to whether the mobile charge carriers are ionic or electronic, repeatod measurements of the same specimen can provide an indication. If conduction is by ions, polarized layers or electrolysis products would accumulate at the electrodes and conduction would decrease as measurement proceeds. Upon repeating the measuring procedure, even after a period of short circuiting and discharge, if would be expected that the subsequent conduction would be less than the first bscause of residual loyers of ions or electrolysis products at the electrodes. That conduction is not by this ionic mechanism is shown in Fig. 8, the behavior of a typical, high-purity polystyrene 


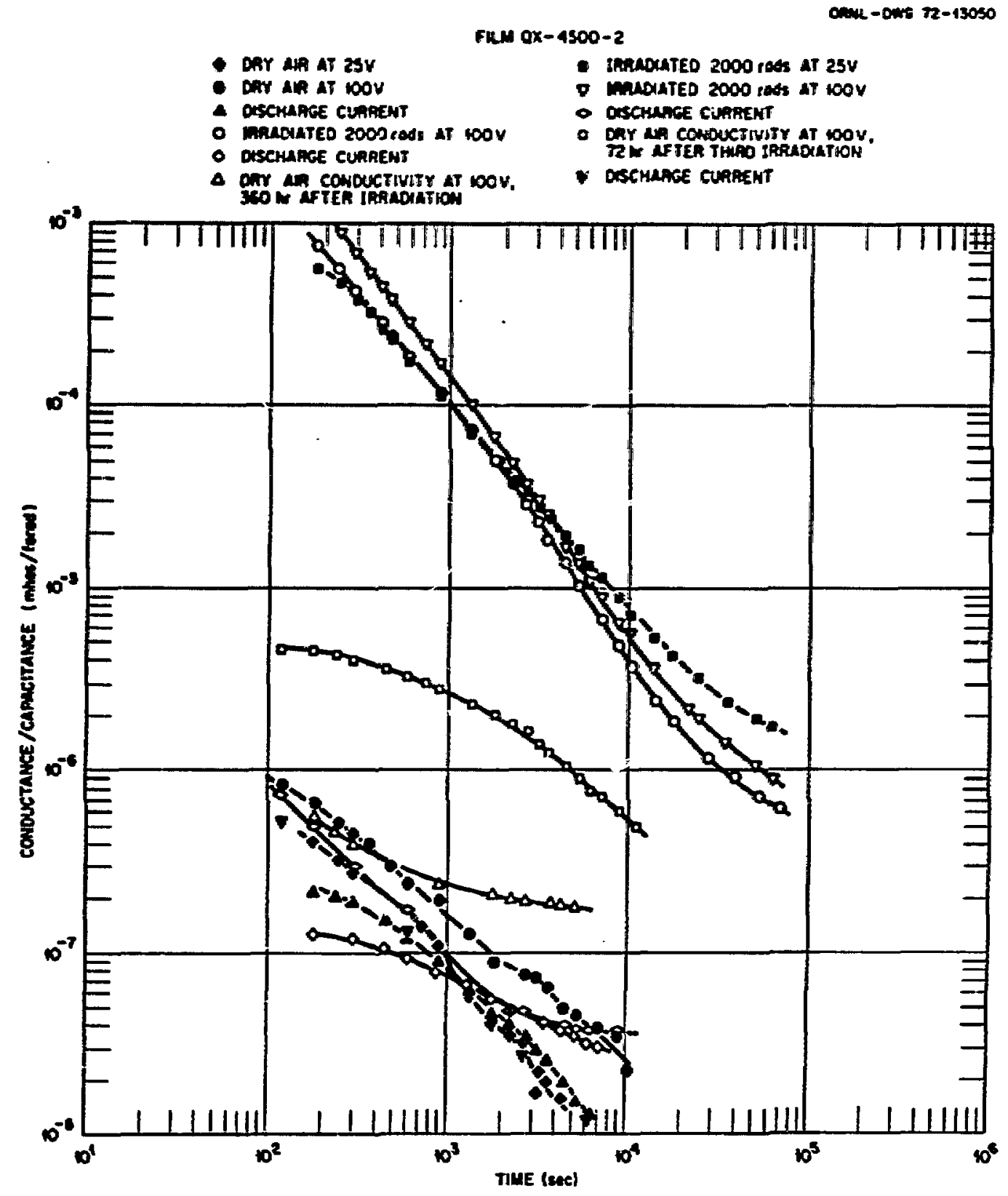

High Purity Pollystyrene, $Q x-4500$. 
subjected to repeated messurement, discharge, and irradiation. Indeed, for periods of several days after irradiation the conduction remained somewhat higher than before irradiation. The behavior of a typical persulfate-initiated, emulsion polystyrene in Fig. $9(a)$ and (b) demonstrates even more conclusively the reproducibility of the conduction curves and the absence of eiectrolytic polarization. It can also be seen from meosurements at 25 and $100 \mathrm{v}$ in Fig. 8 that conductivity is essentially independent of applied voltage, i.e., "Ohmic". The small difference between the curves before irradiation is within the reproducibility of the measurement procedure, and when several specimens were examined differences between conductivities at 25 and $100 \mathrm{v}$ appeared to be random. Independence of voltage has also been reported for conductivity during irradiation. (6)

This overail behavior is strong confirmation of rodiation-generated conduction by either electrons or so-called positive holes. If also indicates that the lower postirradiation conductivity of the $\mathrm{K}_{2} \mathrm{~S}_{2} \mathrm{O}_{8}$-initiated, emulsion copolymer is caused by elimination of charge carriers through recombination or trapping at extraneous entities or non-styrene species.

D. The Effect of Temperature.

The effect of changes in temperature on the apparent conductivity is noteworthy. It would be expected that dielectric charging (without irradiation) would be increased at elevated temperatures because of the greater mobility of molecular segments and polar groups. A much greater increase was observed for the polymers having a higher content of polar groups, including the $\mathrm{K}_{2} \mathrm{~S}_{2} \mathrm{O}_{8}$-initiated, emulsion polymers, as compared to the high-purity, non-polar polymers. On the other hand, post-irratiation conductivity 


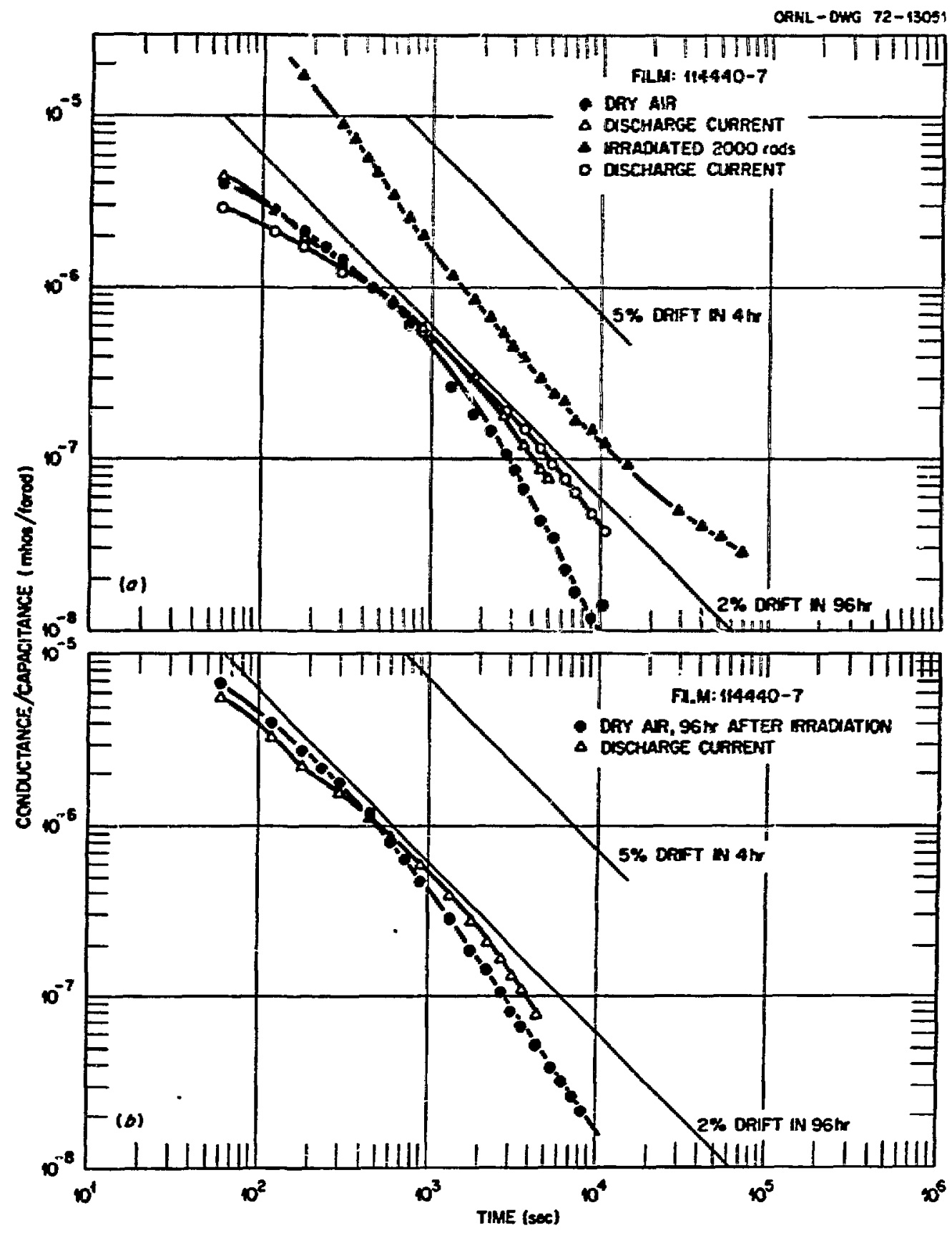

Polystyrene; Inifiofor: $K_{2} S_{2} O_{8}$. Emulsifier: Acto 450, Two Freeze Cycles. 
showed a greater inerease with ternperature for the high-purity polystyrenes than for the $\mathrm{K}_{2} \mathrm{~S}_{2} \mathrm{O}_{8}$-emulsion polystyrene and copolymers.

\section{COMPARISON WTH FOWLER'S TRAP CONTROLLED CONDUCTIVITY THEORY}

An approximate calculation of apparent activation energies for post-irradiation conductivities of the materials above gave values of $1.3-1.4 \mathrm{eV}$ for high-purity polystyrene and 0.9 to $1.0 \mathrm{eV}$ for $\mathrm{K}_{2} \mathrm{~S}_{2} \mathrm{O}_{8}$-emulsion polystyrene and copolymer. These energies are similar to the "equivalent activation energies" measured by Fbwler ${ }^{(1)}$ and attributed to the distribution of trapping levels with respect to energy. From considerations of trapping kinetics he derived equation (1) for the femperature and radiation dependence of conductivity during irradiation:

$$
\sigma=A R^{\Delta} e^{-E^{*} / K T}
$$

in which $A$ and $\Delta$ are constants, $R$ is the dose rafe, and $E^{*}$ is an "equivalent activation energy". For the decay after irradiation, Fowler derived:

$$
\frac{1}{\sigma}=\frac{1}{\sigma_{0}}+\left(\frac{m}{M_{E}}\right) \frac{b t}{k T}
$$

in which $b$ is the recombination rate, $t$ is time after irradiation, $\sigma_{0}$ is conductivity at $t=0, m$ is the number of electrons in traps (a function of time) and $M_{E}$ is the trap concentration (a function of energy levels). For a uniform distribution of traps with respect to energy, Fowler concluded that $E^{*}<1 \mathrm{eV}$, and decay times would be short. For an exponential distribution of traps, $E^{*} \cong 1 \mathrm{eV}$ and the decay time would be much 
longer. Although our activation energies are for post-irradiation conductivity the similarity of values of energies and decay times is suggestive of traps in an exponential energy distribution for the high purity polystyrene and in a uniform distribution for the $\mathrm{K}_{2} \mathrm{~S}_{2} \mathrm{O}_{8}$-emulsion polymers. Although any consideration of trapping or recombination sites in amorphous, non-polar hydrocarbons is speculative at present, it is certainly probable that the emulsion polymers with ionic initiator fragments and residual emulsifier would have a different concentration or energy distribution of trapping or recombination sites than high-purity polystyrene.

\section{IDENTIFICATION OF THE TRAPPING SPECIES OR RECOMBINATION SITE}

A. Occurrence of Polar Constituents.

Infrared spectra and chemical analysis confirmed that ionic impurities remained in the copolymer prepared by emulsion polymerization. Similar analytical work and electrical measurements on different molecular weight fractions precipitated from this copolymer demonstrated that there were only small differences in the composition and post-irradiation conductivities of the various fractions. This indicated that the trapping species was strongly bound to the polymer chain itself.

In $\mathrm{K}_{2} \mathrm{~S}_{2} \mathrm{O}_{8}$-initiated polymerization, the initiation reaction incorporates sulfate groups on the chain ends as follows: 


$$
\begin{aligned}
& 14 \\
& \mathrm{~K}_{2} \mathrm{~S}_{2} \mathrm{O}_{8} \rightarrow 2 \mathrm{~K}^{+}+2 \stackrel{\mathrm{O}-\mathrm{S}-\mathrm{O}^{-}}{\mathrm{O}} \\
& \text { O }
\end{aligned}
$$

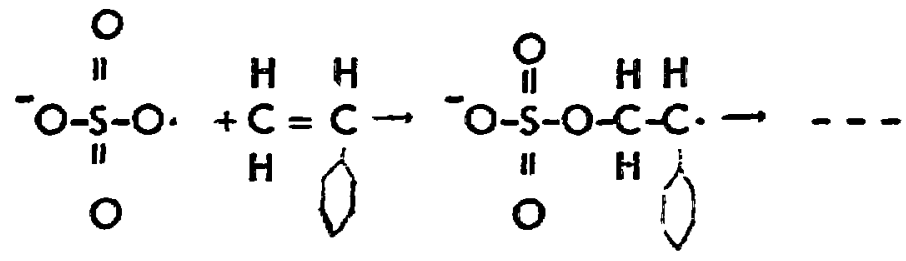

It appears probable, then, that the sulfate end group is involved in the trapping process. This view was substantiated by synthesizing several styrene-based polymers by $\mathrm{K}_{2} \mathrm{~S}_{2} \mathrm{O}_{8}$ initiation but with different emulsifiers, includirg both salts of aliphatic acids (soops) and alkyl aryl sulfonates. The post-irradiation conductivity of all of these was similar, shoving the rapid decay characteristic of effective trapping action. Furthermore, a polystyrene polymerized in aqueous nulsion, but with thermal initiation instead of $\mathrm{K}_{2} \mathrm{~S}_{2} \mathrm{O}_{8^{\prime}}$ showed long-term post-irradiation conductivity similar to high-purity polystyrens.

The dependence of the post-irradiation conductivity on the configuration of comonomer units in the polymer chain itself was investigated by preparing both copolymers of styrene and $\alpha$-methyl styrene and styrene homopolymers by $\mathrm{K}_{2} \mathrm{~S}_{2} \mathrm{O}_{8}$-initiated emulsion polymerization. The electrical properties of these two types of polymers after irradiation did not differ significantly, thus eliminating chain or comonomer configuration as a factor in trapping.

B. Dependence on the Nature of the Polar End Groups.

The dependence of trapping action on the nature of the metallic cation in the end group and the emulsifier was investigated by polymerizations substituting the $\mathrm{NH}_{4}^{+}$ ion for $\mathrm{K}^{+}$and $\mathrm{Na}^{+}$in the persulfate initiator and the alkyl phenyl sulfonate emulsifier. The rapid decay of post-irradiation conductivity indicated trapping action similar to the 
other persulfate-initiated, emulsion polymers, although moisture sensitivity was high and dielectric charging erratic, prior to irradiation, either because of differences in the nature of the ionic groups or because of unfovorable molecular weight distribution.

The entire end group itself was varied (made less polar) by synthesizing polystyrenes in aqueous emulsions initiating with $\mathrm{H}_{2} \mathrm{O}_{2}$ to give $-\mathrm{OH}$ chain ends. The moisture sensitivity of these polymers was variable owing to poor molecular weight control, but following irradiation, the decay of conductivity was more rapid than that of high-purity polystyrenes and for some of these polymers, as rapid as that of $\mathrm{K}_{2} \mathrm{~S}_{2} \mathrm{O}_{8}-$ initiated polymers (Fig. 10). These results indicate that the specific chemical composition of the polar groups does not control the trapping process as long as there is an adequate degree of polarity or ionic character.

\section{INCORPORATION OF POLAR GROUPS ALONG THE POLYMER CHAIN THROUGH COPOLYMERIZATION}

A. Copolymers with Methacrylic Acid and with Maleic Anhydride.

Styrene was copolymerized with methacrylic acid,

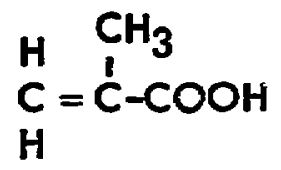

and with maleic anhydride

$$
\begin{gathered}
\mathrm{HC}=\mathrm{CH} \\
\mathrm{O}=\stackrel{!}{\mathrm{C}}_{\mathrm{O}^{\prime}}^{\stackrel{!}{\mathrm{C}}=\mathrm{O}}
\end{gathered}
$$

to incorporate strongly polar acidic or acid anhydride groups along the polymer chain. Di-t-butyl peroxide was used as an initiator giving non-polar end groups and 
ORNL-DWG 71-880!

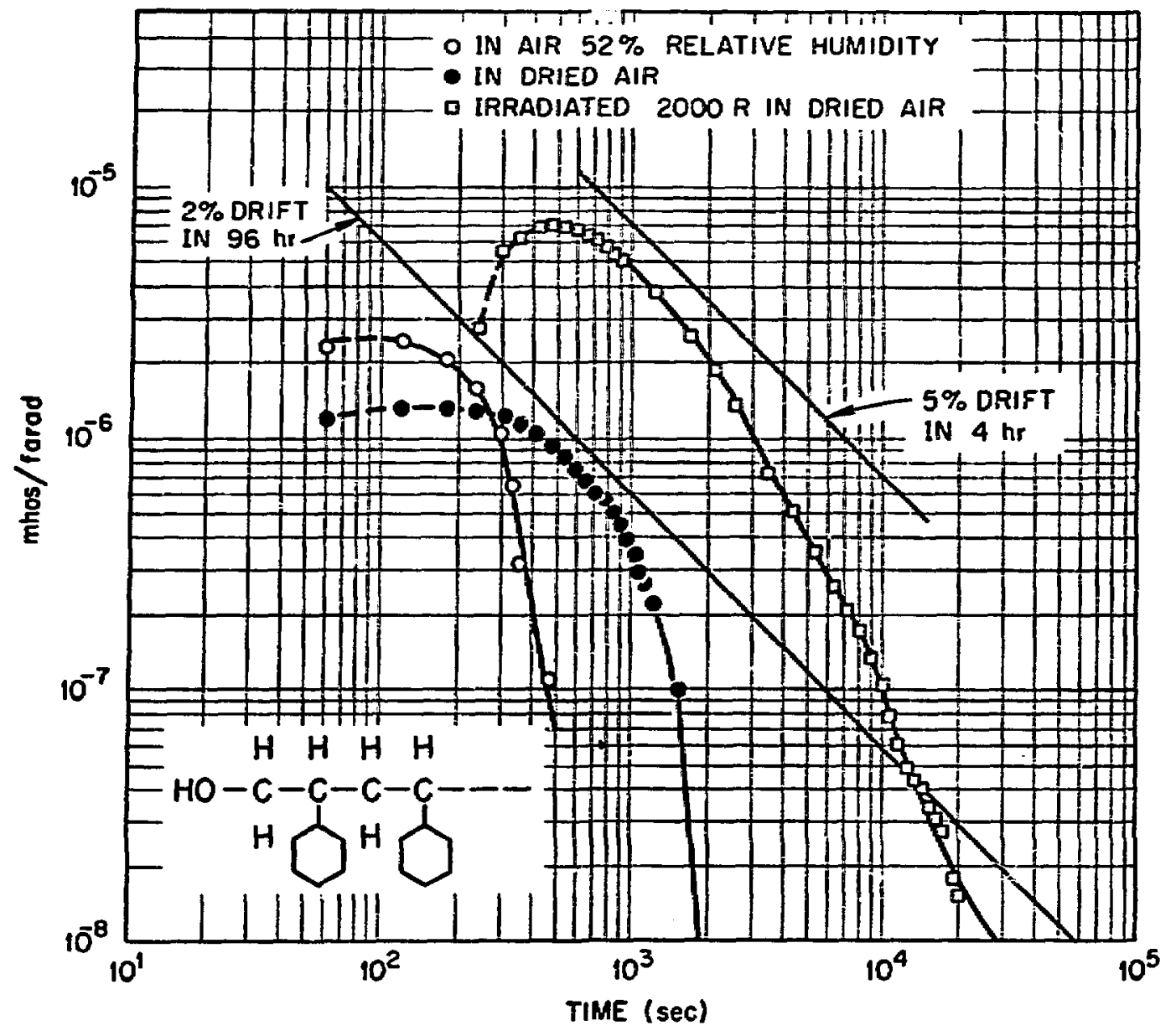

Polystyrene; $\mathrm{H}_{2} \mathrm{O}_{2}$ Initiator, $\mathrm{Na}$ Stearate Emulsifier. 
polymerization was carried out in mass, thereby completely eliminating aqueous emulsifier residues. Although the concentration of polar groups in these polymers was similar to or larger than the concentration of sulfate end groups in $\mathrm{K}_{2} \mathrm{~S}_{2} \mathrm{O}_{8}$-initiated polymers, the post-irradiation conductivity was similar to that of high-purity polystyrene, as shown in Fig. 11, typical of the styrene-methacrylic acid copolymers.

B. Incorporation of Aqueous Emulsifier.

The ineffectiveness of the strongly polar acidic groups as charge carrier traps in these copolymers demonstrated that polar groups alone are not adequate for suppression of post-irradiation conductivity. But in the polymers synthesized in aqueous emulsion, the polar end groups must certainly be associated with the residual emulsifier found in these polymers and probably with water. Therefore, the effect of associated aqueous emulsifier in the acidic copolymers was explored.

Benzene solutions of the methacrylic acid and the maleic acid copolymers were emulsified with refluxing in a water-emulsifier mixture of approximately the same composition as the polymerization recipe. The benzene was boiled off and the polymer phase was separated by freezing-thowing-washing cycles and filtration in a procedure similar to that used in emulsion polymerization.

The post-irradiation conductivity of these copolymers into which aqueous emulsifier had been incorporated (Fig. 12) decayed as rapidly as that of $\mathrm{K}_{2} \mathrm{~S}_{2} \mathrm{O}_{8}$ emulsion polystyrene. Furthermore, specimens prepared from benzene solutions of acidic copolymers which had been neutralized and suspended in water, behaved similarly, although their mechanical and electrical properties without irradiation were relatively poor. These results indicate the strongly polar acidic groups can be 


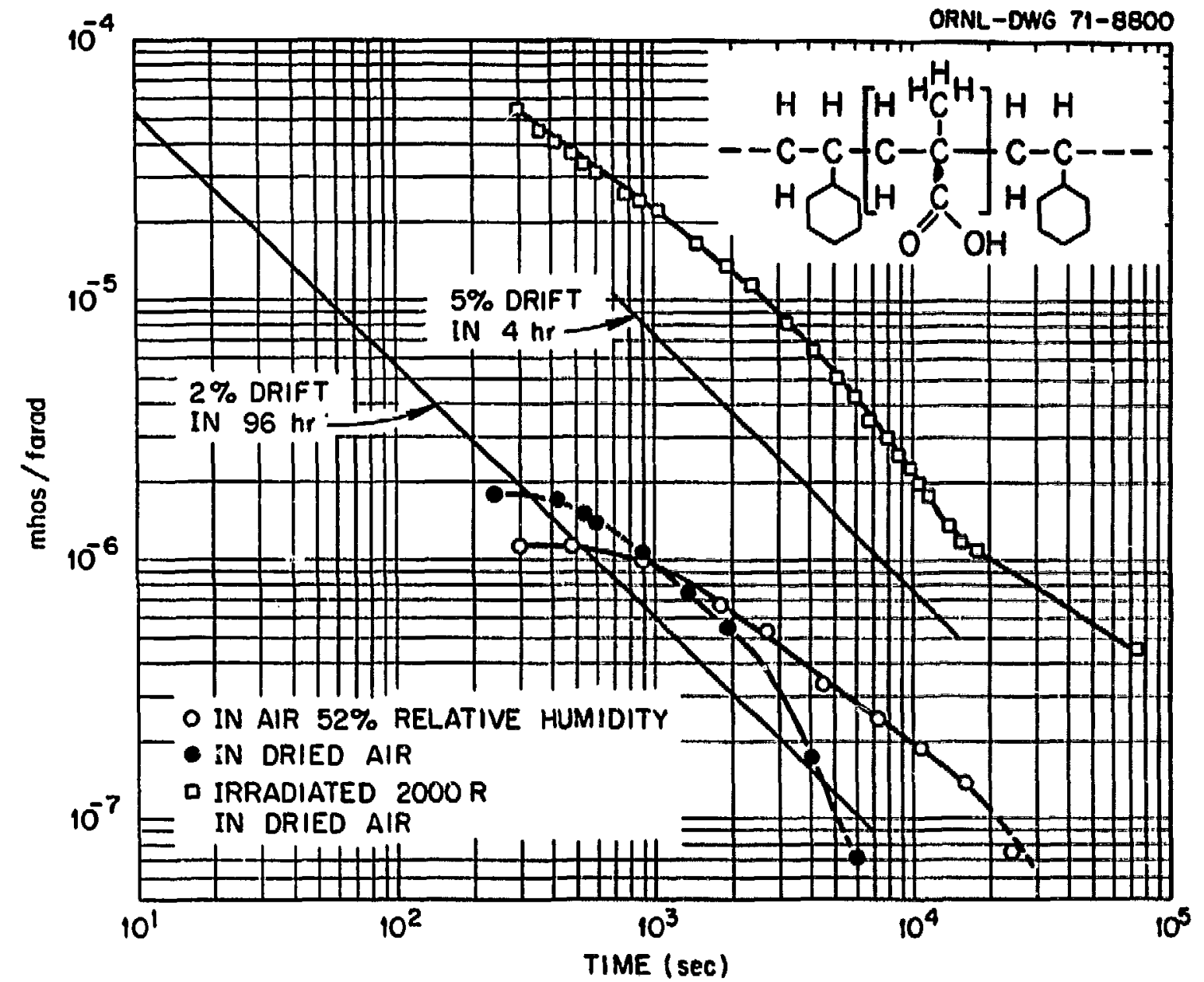

Copolymer: Styrene-Methocrylic Acid $(1.0 w \uparrow \%)$ Moss Polymerized, Dibutyl Peroxide. 


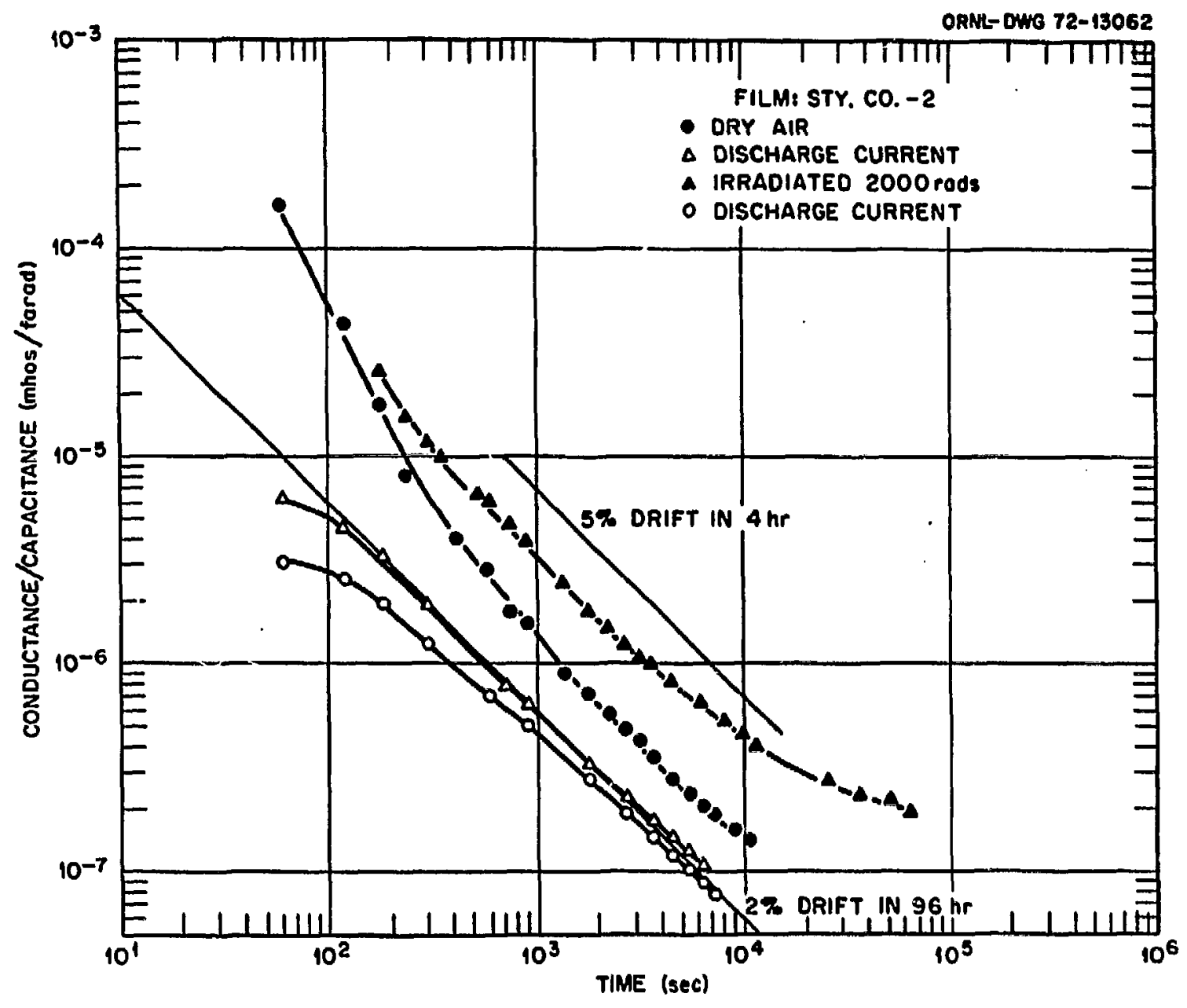

Styrene-Maleic Anhydride (0.5 wt \%) Copolymer, Mass Polymerized, $\mathrm{C}_{6} \mathrm{H}_{6}$ Solution Neutralized with $\mathrm{NoOH}$ in $\mathrm{H}_{2} \mathrm{O}$ Emulsion-Acto 450. 
converted into effective tropping sites by incorporation of an associated aqueous or emulsifier phase.

\section{CONCLUSIONS}

Post-irradiatio., conductivity in styrene-based polymers is by electrons or "holes" and the decay of conductivity can be influenced by incorporation of suitable trapping species in the polymer. Polar groups are an essential constituent of effective traps, or confer a proper distribution of energy levels, but the specific chemical nature of the elements in the groups does not appear to be important.

The polar nature of the substances found to be effective traps makes it likely that they are insoluble in the amorphous polymer matrix and form a second phase. The requirement for an inhomogeneous system is also indicated by the absence of effective trapping in the acidic copolymers. For proper uniformity and degree of dispersal of these polar substituents, incorporation of polar groups on the polymer chain itself appears to be required. Inasmuch as the polymers in this study which demonstrated effective trapping had all been prepared from an aqueous emulsion or suspension, it seems probable that the traps were composed of a highly dispersed water-emulsifier phase, associated with the polar groups on the polymer chain. 
18

REFERENCES

1. J. L. Fowler, Proc. Roy. Soc., (London) A-236, 464 (1956).

2. J. A. Ghormley and C. J. Hochanadel, Rev. Sci. Inst. 22, 473 (1953).

3. Vera V. Daniel, "Dielectric Relaxation", Academic Press, New York (1967).

4. H. Frohlich, "Theory of Dielectrics", Oxford Univ. Press, London (1958).

5. V. Adamec, J. Pol. Science, Pt. A-2, 6, 1241 (1968). 


\section{LST OF FIGURES}

Fig. 1 Block Diagram of Circuit for Measurement of Electrical Properties.

Fig. 2 Typical Specimen Film with Rectangular Electrodes.

Fig. 3 Apparent Conductivities (Dielectric Charging) of Typical Polymeric Materials, Unirradiated.

Fig. 4 Apparent Conductivities of Typical Polymeric Materials After Irradiation.

Fig. 5 Typical Behavior of Conductivities of High Purity Polystyrene Upon Short Circuiting or Reversing Applied Potential.

Fig. 6 Apparent Conductivity of High-Purity Polystyrene Upon Delaying Application of Potential After Irratiation.

Fig. 7 Apparent Conductivity of $\mathrm{K}_{2} \mathrm{~S}_{2} \mathrm{O}_{8}$-Initiated, Emulsion Polystyrene Upon Delaying Application of Potential After Irradiation.

Fig. 8. Conductivities of High-Purity Polystyrene After Repeated Irradiation and Measurement.

Fig. 9 Conductivities of $\mathrm{K}_{2} \mathrm{~S}_{2} \mathrm{O}_{8}$-Initiated, Emulsion Polystyrene (a) Before and After Irradiation, (b) Remeasurement 96 Hours After Irradiation and Measurement.

Fig. 10 Conductivities of Polystyrene Prepared with $\mathrm{H}_{2} \mathrm{O}_{2}$ Initiator and Sodium Stearate Emulsifier.

Fig. 11 Conductivities of Styrene-Methacrylic Acid (1.0 w\%) Copolymer.

Fig. 12 Conductivities of Styrene-Maleic Anhydride (0.5 wt\%) Copolymer, Neutralized with $\mathrm{NaOH}$ in $\mathrm{H}_{2} \mathrm{O}$ Emulsion. 